\title{
OBSERVATION OF A BROWN THRASHER NEST (TOXOSTOMA RUFUM) ON STATIONARY FARM EQUIPMENT
}

Jamie Rothenburger ${ }^{1}$ and Tex Rothenburger

1. 50 Stone Road, Department of Pathobiology, Ontario Veterinary College, University of Guelph, Guelph, Ontario, Canada, N1G 2W1 Email: jamie.rothenburger@gmail.com

On June 20, 2015, at 14:00h, a brown thrasher (Toxostoma rufum) nest was discovered containing 5 eggs (Fig. 1). The nest was situated on a stationary 1939 Model 30 Cockshutt tractor, immediately adjacent to the battery case alongside the starter and hydraulic tank (Fig. 2). The tractor was parked during the winter at an acreage in Pasqua, Saskatchewan $\left(50^{\circ} 22^{\prime} 29^{\prime \prime} \mathrm{N}\right.$, $105^{\circ} 22^{\prime} 54^{\prime \prime} \mathrm{W}$ ), a hamlet located $13 \mathrm{~km}$ east of Moose Jaw and it had not been moved since. By 06:00h on June 21, 2015, two eggs hatched and these chicks were within the nest. The remaining three eggs were intact. Two apparently healthy young were last seen within the nest on July 6, 2015 at 15:00h. The female aggressively guarded the nest at each of these observations. As of July 8,2015 , the female and young were gone. Typical nesting locations for the brown thrasher include low shrubs, small trees and rarely on the ground. To our knowledge, this is the first report of a brown thrasher nesting on farm equipment.

\section{Acknowledgement}

We wish to thank C. Stuart Houston for encouraging us to write this report.

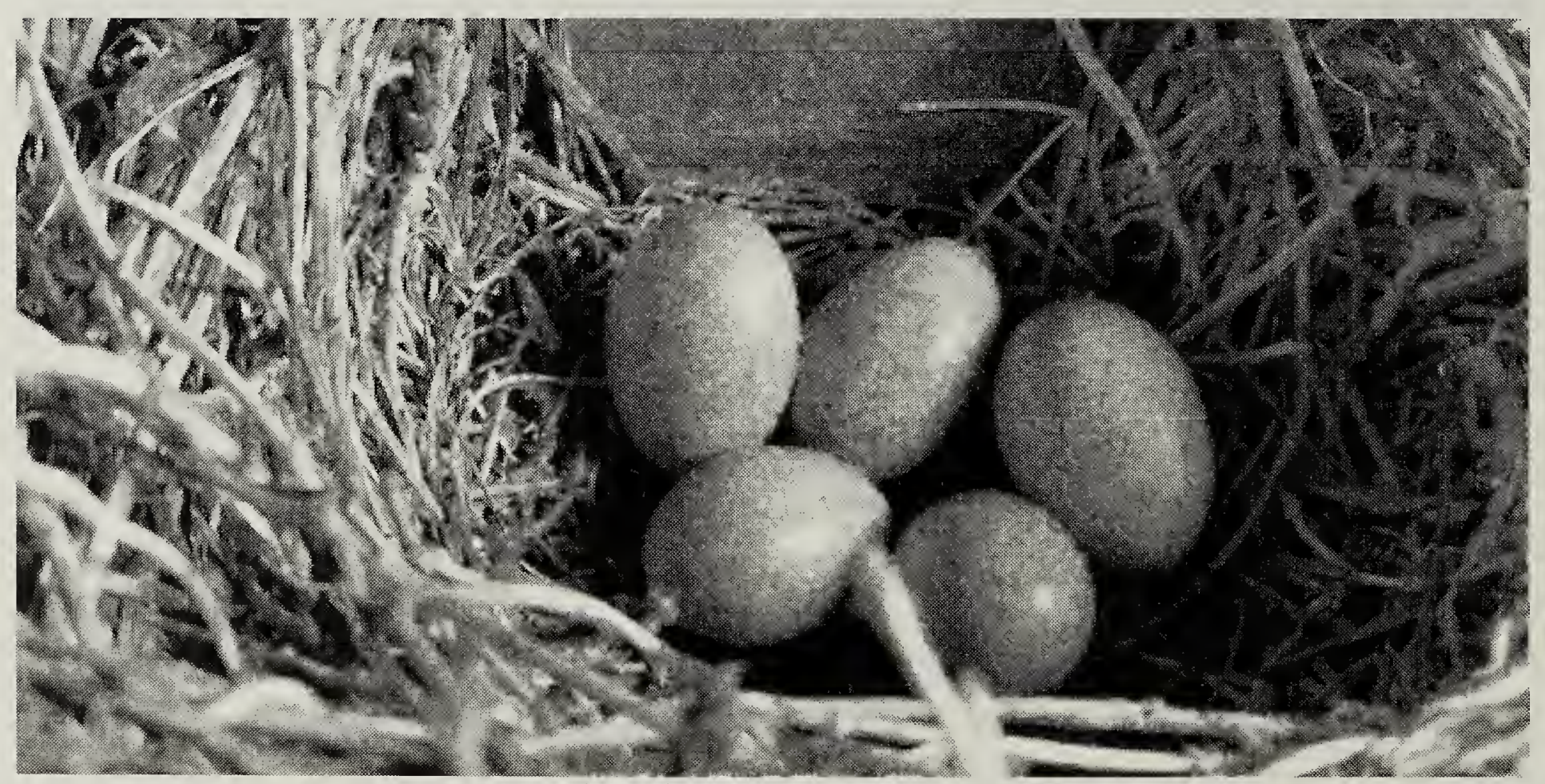

- Jamie Rothenburger and Tex Rothenburger 


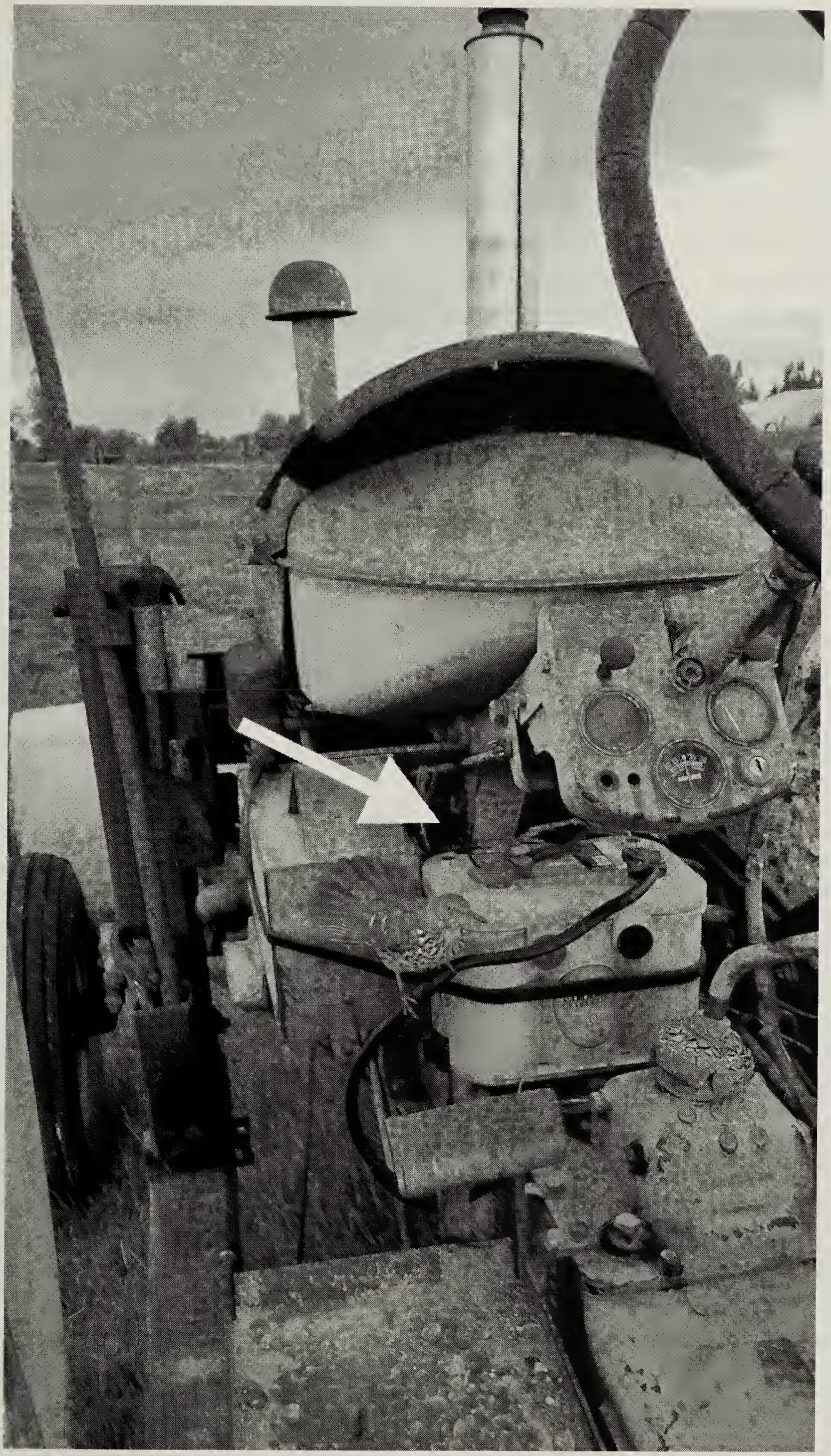

- Jamie Rothenburger and Tex Rothenburger 